\title{
Structure of replicating SARS-CoV-2 polymerase
}

https://doi.org/10.1038/s41586-020-2368-8

Received: 27 April 2020

Accepted: 15 May 2020

Published online: 21 May 2020

Check for updates

\author{
Hauke S. Hillen ${ }^{1,2}$, Goran Kokic ${ }^{1,2}$, Lucas Farnung ${ }^{1,2}$, Christian Dienemann $^{1,2}$, Dimitry Tegunov ${ }^{1,2}$ \\ \& Patrick Cramer ${ }^{1 凶}$
}

The new coronavirus severe acute respiratory syndrome coronavirus 2 (SARS-CoV-2) uses an RNA-dependent RNA polymerase (RdRp) for the replication of its genome and the transcription of its genes ${ }^{1-3}$. Here we present a cryo-electron microscopy structure of the SARS-CoV-2 RdRp in an active form that mimics the replicating enzyme. The structure comprises the viral proteins non-structural protein 12 (nsp12), nsp8 and nsp7, and more than two turns of RNA template-product duplex. The active-site cleft of nsp12 binds to the first turn of RNA and mediates RdRp activity with conserved residues. Two copies of nsp8 bind to opposite sides of the cleft and position the second turn of RNA. Long helical extensions in nsp8 protrude along exiting RNA, forming positively charged 'sliding poles'. These sliding poles can account for the known processivity of RdRp that is required for replicating the long genome of coronaviruses ${ }^{3}$. Our results enable a detailed analysis of the inhibitory mechanisms that underlie the antiviral activity of substances such as remdesivir, a drug for the treatment of coronavirus disease 2019 (COVID-19) ${ }^{4}$.
Coronaviruses are positive-strand RNA viruses that pose a major health risk $^{1}$ : SARS-CoV-2 has caused a pandemic of the disease known as COVID-195,6. Coronaviruses use an RdRp complex for the replication of their genome and for the transcription of their genes ${ }^{2,3}$. This RdRp complex is the target of nucleoside analogue inhibitors-in particular, remdesivir ${ }^{7,8}$. Remdesivir inhibits the RdRp of multiple coronaviruses $^{9,10}$, and shows antiviral activity in cell culture and animal models ${ }^{11}$. Remdesivir is currently being tested in the clinic in many countries ${ }^{12}$ and has recently been approved for emergency treatment of patients with COVID-19 in the United States ${ }^{4}$.

The RdRp of SARS-CoV-2 is composed of a catalytic subunit known as $\mathrm{nsp} 12^{13}$ as well as two accessory subunits, $\mathrm{nsp} 8$ and $\mathrm{nsp} 7^{3,14}$. The structure of this RdRp has recently been reported ${ }^{15}$; it is highly similar to the RdRp of SARS-CoV ${ }^{16}$, a zoonotic coronavirus that spread into the human population in $2002^{1}$. The nsp12 subunit contains an $\mathrm{N}$-terminal nidovirus RdRp-associated nucleotidyltransferase (NiRAN) domain, an interface domain and a C-terminal RdRp domain ${ }^{15,16}$. The RdRp domain resembles a right hand, comprising the fingers, palm and thumb subdomains ${ }^{15,16}$ that are found in all single-subunit polymerases. Subunits nsp7 and nsp 8 bind to the thumb, and an additional copy of nsp 8 binds to the fingers domain ${ }^{15,16}$. Structural information is also available for nsp8-nsp7 complexes ${ }^{17,18}$.

To obtain the structure of the SARS-CoV-2 RdRp in its active form, we prepared recombinant nsp12, nsp8 and nsp7 (Fig. 1a, Methods). When added to a minimal RNA hairpin substrate (Fig. 1b), the purified proteins gave rise to RNA-dependent RNA extension activity, which depended on nsp8 and nsp7 (Fig.1c). We assembled and purified a stable RdRp-RNA complex with the use of a self-annealing RNA, and collected single-particle cryo-electron microscopy (cryo-EM) data (Extended Data Fig. 1, Extended Data Table 1). Particle classification yielded a 3D reconstruction at a nominal resolution of $2.9 \AA$ (Extended Data Fig. 1).
This led to a refined structure of the RdRp-RNA complex that showed the RNA in the active centre in great detail (Extended Data Fig. 2).

Our structure shows the RdRp enzyme engaged with over two turns of duplex RNA (Fig. 2, Supplementary Video 1). The structure resembles that of the free enzyme ${ }^{15}$, but additionally reveals a long protruding RNA and extended protein regions in nsp8 (Extended Data Fig. 3a). To our knowledge, these observations are unique: the RdRp complexes of hepatitis $\mathrm{C}$ virus ${ }^{19}$, poliovirus ${ }^{20}$ and norovirus ${ }^{21}$ contain only one turn of RNA, and show no features that resemble the newly observed nsp8 extensions (Extended Data Fig. 3b).

Our structure provides details of the interactions between the RdRp and RNA (Fig. 3). The nsp12 subunit binds to the first turn of RNA between its fingers and thumb subdomains (Fig. 3a,b). The active site is located on the palm subdomain, and is formed by five conserved nsp12 elements known as motifs A-E (Fig. 3b). Motif C binds to the RNA3' end and contains the residues D760 and D761, which are required for RNA synthesis ${ }^{10,14}$. The additional nsp 12 motifs $F$ and $G$ reside in the fingers subdomain and position the RNA template (Fig. 3b). The observed contacts of nsp12 with the RNA product strand may retain short RNA during early steps of RNA synthesis.

As the RNA duplex exits from the RdRp cleft, it forms a second helical turn that protrudes from the nsp12 surface (Fig. $3 \mathrm{c}$ ). There are no structural elements in the RdRp that restrict the extension of the RNA duplex. These observations are consistent with the production of double-stranded RNA during replication. However, it is unclear whether replication in infected cells results in RNA duplexes or whether RNA strands are separated and-if so-how. It is also unknown when and how RNA strands are separated during the transcription of viral genes, which produces single-stranded product mRNAs that can be translated.

The protruding, exiting RNA duplex is flanked by long $\alpha$-helical extensions that are formed by the highly conserved ${ }^{17} \mathrm{~N}$-terminal regions in 


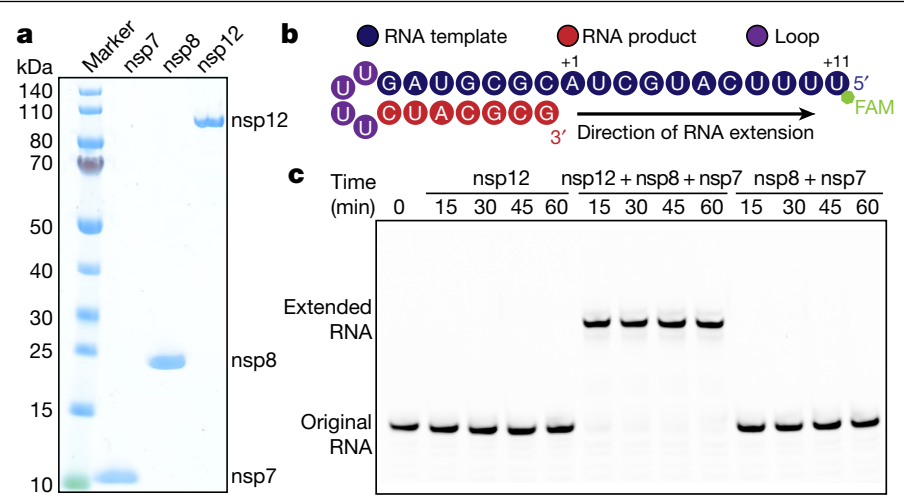

Fig. 1 Preparation of active SARS-CoV-2 RdRp. a, SDS-PAGE analysis of the purified SARS-CoV-2 RdRp subunits nsp12, nsp8 and nsp7. The experiment was performed once. $\mathbf{b}$, Minimal RNA substrate that folds into a hairpin with 'template' and 'product' regions. The RNA contains a 11-nucleotide, fluorescently labelled 5' overhang. c, Incubation of the RdRp subunits (a) with RNA (b) leads to efficient RNA extension. RNAs were separated on a denaturing acrylamide gel and visualized with a Typhoon 95000 FLA Imager. Representative result of three independent technical replicates (Supplementary Fig. 1).

the two nsp8 subunits (Figs. 2,3). These prominent nsp8 extensions reach up to 28 base pairs away from the active site and use positively charged residues that are positioned to interact with the RNA backbones (Fig. 3). The two nsp8 extensions differ with respect to their RNA interactions, which also argues for sequence-independent binding. The two nsp8 copies adopt different structures in the RdRp complex, and interact differently with nsp7 and nsp12 subdomains (Extended Data Fig. 3c). The nsp8 extensions also adopt different structures in crystals of nsp8-nsp7 complexes ${ }^{17,18}$, and are mobile in free RdRp ${ }^{15,16}$. This indicates that the nsp 8 extensions are flexible in the RdRp complex and become ordered when an RNA duplex exits the enzyme.

The interactions of the nsp8 extensions with exiting RNA may explain the processivity of the RdRp, which is required for replicating the very long RNA genome of coronaviruses and other viruses of the Nidovirales order $^{3}$. It is known that nsp8 and nsp7 confer processivity to nsp12 $2^{14}$. It is also known that the substitution of the nsp8 residue $\mathrm{K} 58$ with alanine is lethal for the virus ${ }^{14}$. $\mathrm{K} 58$ is located in the nsp8 extension, and interacts with exiting RNA around the minor groove (Fig. $3 \mathrm{c}$ ). The nsp8 extensions may be regarded as sliding poles, which slide along exiting RNA to prevent premature dissociation of the RdRp during replication. The sliding poles may serve a function similar to the 'sliding clamps' that confer processivity to DNA replication machines ${ }^{22}$.

To investigate how the RdRp binds to the incoming nucleoside triphosphate (NTP) substrate, we superimposed our structure onto the related structure of the norovirus RdRp-nucleic acid complex ${ }^{21}$. This suggested that the NTP-binding site is conserved, including putative contacts between nsp12 and the NTP (Extended Data Fig. 3d, Supplementary Video 2). Residues N691, S682 and D623 may recognize the $2^{\prime}-\mathrm{OH}$ group of the NTP, thereby rendering the RdRp specific for the synthesis of RNA rather than DNA. Our modelling is also consistent with binding of the triphosphorylated form of remdesivir to the NTP site, because there is space to accommodate the additional nitrile group that is present at the $1^{\prime}$ position of the ribose ring of remdesivir (Extended Data Fig. 3d).

While our manuscript was under review, the structure of another SARS-CoV-2 RdRp-RNA complex became available ${ }^{23}$ and was published soon thereafter ${ }^{24}$. Comparison of the two studies shows that the core structures are similar; however, we additionally observe a second turn of RNA and the nsp8 sliding poles. The other study suggests that remdesivir functions as an 'immediate' RNA-chain terminator ${ }^{23,24}$. However, published biochemistry has shown that several more nucleotides can be added to RNA after incorporation of remdesivir, leading to 'delayed'

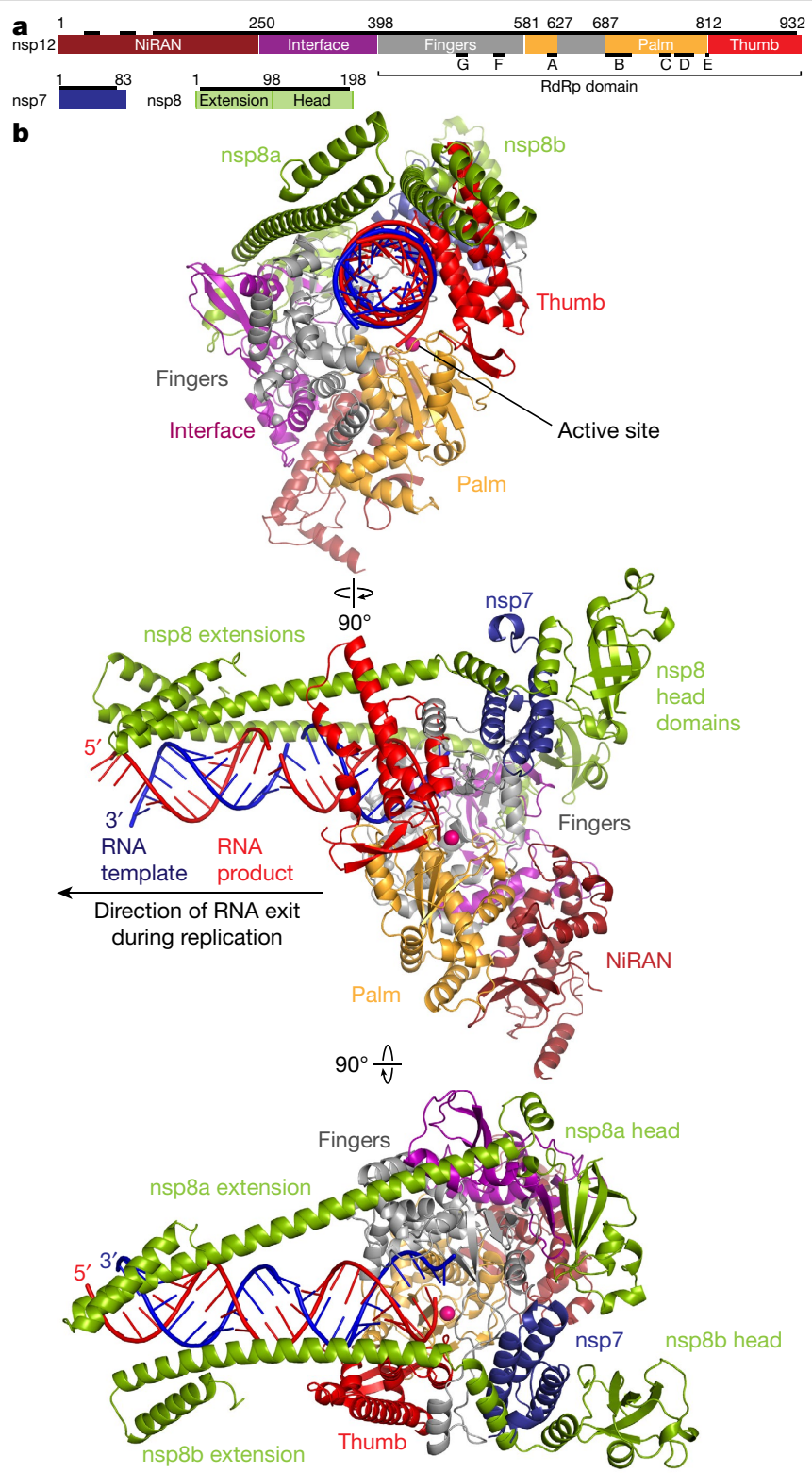

Fig. 2 | Structure of complex between SARS-CoV-2 RdRp and RNA. a, Domain structure of nsp12, nsp8, and nsp7 subunits of RdRp. In nsp12, the conserved sequence motifs $A-\mathrm{G}^{16}$ are depicted. Regions included in the structure are indicated with black bars. b, Three views of the structure, related by $90^{\circ}$ rotations (top, back view; middle, side view; bottom, top view). Colour code for nsp12 (NiRAN, interface, fingers, palm and thumb), nsp8, nsp7, RNA template (blue) and RNA product (red) used throughout. The magenta sphere depicts a modelled ${ }^{21}$ metal ion in the active site.

termination ${ }^{10,25}$. We note that this latter mechanism can explain how remdesivir escapes removal from the RNA 3' end by the viral exonuclease $n s p 14^{26}$ that binds to the RdRp complex ${ }^{14}$. On the basis of the results presented here, mechanistic questions regarding coronavirus replication, transcription and antiviral targeting can now be investigated.

\section{Online content}

Any methods, additional references, Nature Research reporting summaries, source data, extended data, supplementary information, acknowledgements, peer review information; details of author contributions and competing interests; and statements of data and code availability are available at https://doi.org/10.1038/s41586-020-2368-8. 

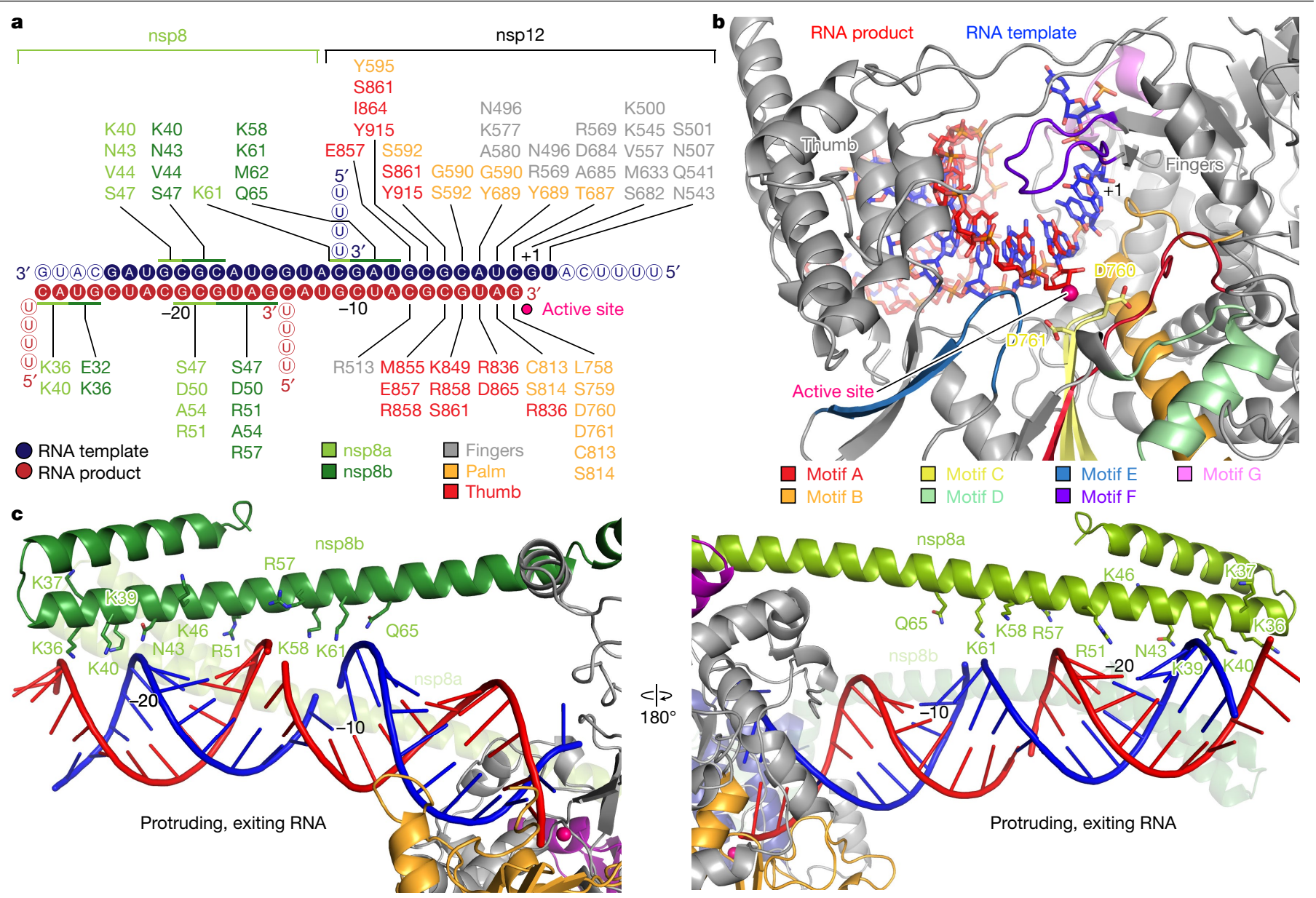

Fig. 3 | RdRp-RNA interactions. a, Schematic of protein-RNA interactions. Solid and hollow circles show nucleotides that were included in the structure or invisible, respectively. RNA is assembled from overlapping oligonucleotides (Extended Data Fig. 1c). RdRp residues in nsp12 within 4 Å of RNA are indicated and contacts are depicted with lines. Nsp8 residues and their putative RNA contact regions (horizontal lines, within $5 \AA$ ) are indicated even if side chain

density is absent. $\mathbf{b}$, Interactions of the RdRp active site with the first turn of RNA. Subunit nsp12 is in grey, and conserved motifs A-G are coloured. Active-site residues D760 and D761 shown as sticks. The magenta sphere depicts a modelled ${ }^{21}$ metal ion. c, Charged nsp 8 residues that may interact with proximal RNA regions. Left, side view; right, inverted side view.
1. Hilgenfeld, R. \& Peiris, M. From SARS to MERS: 10 years of research on highly pathogenic human coronaviruses. Antiviral Res. 100, 286-295 (2013).

2. Snijder, E. J., Decroly, E. \& Ziebuhr, J. The nonstructural proteins directing coronavirus RNA synthesis and processing. Adv. Virus Res. 96, 59-126 (2016).

3. Posthuma, C. C., Te Velthuis, A. J. W. \& Snijder, E. J. Nidovirus RNA polymerases: complex enzymes handling exceptional RNA genomes. Virus Res. 234, 58-73 (2017).

4. Ledford, H. Hopes rise for coronavirus drug remdesivir. Nature https://doi.org/10.1038/ d41586-020-01295-8 (2020).

5. Wu, F. et al. A new coronavirus associated with human respiratory disease in China. Nature 579, 265-269 (2020).

6. Zhou, P. et al. A pneumonia outbreak associated with a new coronavirus of probable bat origin. Nature 579, 270-273 (2020).

7. Subissi, L. et al. SARS-CoV ORF1b-encoded nonstructural proteins 12-16: replicative enzymes as antiviral targets. Antiviral Res. 101, 122-130 (2014).

8. Jordan, P. C., Stevens, S. K. \& Deval, J. Nucleosides for the treatment of respiratory RNA virus infections. Antivir. Chem. Chemother. 26, 1-19 (2018).

9. Agostini, M. L. et al. Coronavirus susceptibility to the antiviral remdesivir (GS-5734) is mediated by the viral polymerase and the proofreading exoribonuclease. MBio 9 , e00221-18 (2018)

10. Gordon, C. J., Tchesnokov, E. P., Feng, J. Y., Porter, D. P. \& Götte, M. The antiviral compound remdesivir potently inhibits RNA-dependent RNA polymerase from Middle East respiratory syndrome coronavirus. J. Biol. Chem. 295, 4773-4779 (2020).

11. Sheahan, T. P. et al. Broad-spectrum antiviral GS-5734 inhibits both epidemic and zoonotic coronaviruses. Sci. Transl. Med. 9 , eaal3653 (2017).

12. Kupferschmidt, K. \& Cohen, J. Race to find COVID-19 treatments accelerates. Science 367, 1412-1413 (2020).

13. Ahn, D. G. Choi, J. K. Taylor, D. R. \& Oh, J. W. Biochemical characterization of a recombinant SARS coronavirus nsp12 RNA-dependent RNA polymerase capable of copying viral RNA templates. Arch. Virol. 157, 2095-2104 (2012).

14. Subissi, L. et al. One severe acute respiratory syndrome coronavirus protein complex integrates processive RNA polymerase and exonuclease activities. Proc. Natl Acad. Sci. USA 111, E3900-E3909 (2014).
15. Gao, Y. et al. Structure of the RNA-dependent RNA polymerase from COVID-19 virus. Science 368, 779-782 (2020).

16. Kirchdoerfer, R. N. \& Ward, A. B. Structure of the SARS-CoV nsp12 polymerase bound to nsp7 and nsp8 co-factors. Nat. Commun. 10, 2342 (2019).

17. Zhai, Y. et al. Insights into SARS-CoV transcription and replication from the structure of the nsp7-nsp8 hexadecamer. Nat. Struct. Mol. Biol. 12, 980-986 (2005).

18. Xiao, Y. et al. Nonstructural proteins 7 and 8 of feline coronavirus form a 2:1 heterotrimer that exhibits primer-independent RNA polymerase activity. J. Virol. 86, 4444-4454 (2012).

19. Appleby, T. C. et al. Structural basis for RNA replication by the hepatitis $\mathrm{C}$ virus polymerase. Science 347, 771-775 (2015).

20. Gong, P. \& Peersen, O. B. Structural basis for active site closure by the poliovirus RNA-dependent RNA polymerase. Proc. Natl Acad. Sci. USA 107, 22505-22510 (2010).

21. Zamyatkin, D. F., Parra, F., Machín, A., Grochulski, P. \& Ng, K. K. Binding of 2'-amino2'-deoxycytidine-5'-triphosphate to norovirus polymerase induces rearrangement of the active site. J. Mol. Biol. 390, 10-16 (2009).

22. Moldovan, G. L., Pfander, B. \& Jentsch, S. PCNA, the maestro of the replication fork. Cell 129, 665-679 (2007)

23. Yin, W. et al. Structural basis for the inhibition of the RNA-dependent RNA polymerase from SARS-CoV-2 by remdesivir. Preprint at bioRxiv https://doi.org/10.1101/2020. $04.08 .032763(2020)$

24. Yin, W. et al. Structural basis for inhibition of the RNA-dependent RNA polymerase from SARS-CoV-2 by remdesivir. Science 368, 1499-1504 (2020).

25. Tchesnokov, E. P., Feng, J. Y., Porter, D. P. \& Götte, M. Mechanism of inhibition of Ebola virus RNA-dependent RNA polymerase by remdesivir. Viruses 11, 326 (2019).

26. Bouvet, M. et al. RNA $3^{\prime}$-end mismatch excision by the severe acute respiratory syndrome coronavirus nonstructural protein nsp10/nsp14 exoribonuclease complex. Proc. Natl Acad. Sci. USA 109, 9372-9377(2012).

Publisher's note Springer Nature remains neutral with regard to jurisdictional claims in published maps and institutional affiliations.

(c) The Author(s), under exclusive licence to Springer Nature Limited 2020 


\section{Methods}

No statistical methods were used to predetermine sample size. The experiments were not randomized, and the investigators were not blinded to allocation during experiments and outcome assessment.

\section{Cloning and protein expression}

The SARS-CoV-2 nsp12 gene was codon-optimized for expression in insect cells. The SARS-CoV-2nsp8 and $n s p 7$ genes were codon-optimized for expression in Escherichia coli. Synthesis of genes was performed by GeneArt (Thermo Fisher Scientific GENEART). The gene synthesis products of the respective genes were PCR amplified with ligation-independent cloning-compatible primer pairs ( $n s p 12$ : forward primer:5'-TACTTCCAATCCAATGCATCTGCTGACGCTCAGTCCTTCCTG -3', reverse primer: $5^{\prime}$-TTATCCACTTCCAATGTTATTATTGCAGCACG GTGTGAGGGG-3'; $n s p 8$ : forward primer: 5'-TACTTCCAATCCAATGCAG CAATTGCAAGCGAATTTAGCAGCCTG-3', reverse primer: 5'-TTATCCACTTCCAATGTTATTACTG CAGTTTAACTGCGCTATTTG CACG-3'; $n s p 7$ : forward primer: 5'-TACTTCCAATCCAATGCAAGCAA AATGTCCGATGTTAAATGCACCAGC-3', reverse primer: 5'-TTATCCACTTCCAATGTTATTACTGCAGGGTTGCACGATTATCCAGC $\left.-3^{\prime}\right)$. The PCR products for $n s p 8$ and $n s p 7$ were individually cloned into the pET-derived vector 14-B (a gift from S. Gradia; Addgene 48308). The two constructs for nsp8 and nsp7 contain an $\mathrm{N}$-terminal $6 \times \mathrm{His}$ tag and a tobacco etch virus (TEV) protease cleavage site. The PCR product containing codon-optimized nsp12 was cloned into the modified pFastBac vector 438-C (a gift from S. Gradia; Addgene 55220) via ligation-independent cloning. The nsp12 construct contained an $\mathrm{N}$-terminal $6 \times$ His tag, followed by an MBP tag, a $10 \times$ Asp sequence and a TEV protease cleavage site. All constructs were verified by sequencing.

The SARS-CoV-2 nsp12 plasmid (500 ng) was transformed into DH10EMBacY cells using electroporation to generate a bacmid encoding full-length nsp12. Virus production and expression in insect cells was then performed as previously described ${ }^{27}$. Insect cell lines were obtained from Expression Systems (94-002F and 94-003F) or Thermo Fisher (12659017). Cell lines were not authenticated. No commonly misidentified cell lines were used. After 60 h of expression in $\mathrm{Hi} 5$ cells, cells were collected by centrifugation and resuspended in lysis buffer (300 mM NaCl, 50 mM Na-HEPES pH 7.4, 10\% (v/v) glycerol, $30 \mathrm{mM}$ imidazole $\mathrm{pH}$ 8.0, $3 \mathrm{mM} \mathrm{MgCl}_{2}, 5 \mathrm{mM} \beta$-mercaptoethanol, $0.284 \mathrm{\mu g} \mathrm{ml}^{-1}$ leupeptin, $1.37 \mu \mathrm{g} \mathrm{ml}^{-1}$ pepstatin, $0.17 \mathrm{mg} \mathrm{ml}^{-1} \mathrm{PMSF}$, and $0.33 \mathrm{mg} \mathrm{ml}^{-1}$ benzamidine). The SARS-CoV-2 nsp8 and nsp7 plasmids were overexpressed in E. coli BL21 (DE3) RIL cells grown in LB medium. Cells were grown to an optical density at $600 \mathrm{~nm}$ of 0.6 at $37^{\circ} \mathrm{C}$ and protein expression was subsequently induced with $0.5 \mathrm{mM}$ isopropyl $\beta$-D-1-thiogalactopyranoside at $18^{\circ} \mathrm{C}$ for $16 \mathrm{~h}$. Cells were collected by centrifugation and resuspended in lysis buffer $(300 \mathrm{mM} \mathrm{NaCl}, 50 \mathrm{mM}$ Na-HEPES pH 7.4, 10\% (v/v) glycerol, $30 \mathrm{mM}$ imidazole $\mathrm{pH} 8.0,5 \mathrm{mM}$

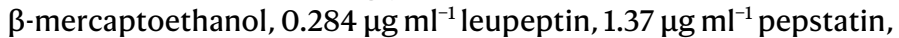
$0.17 \mathrm{mg} \mathrm{ml}^{-1}$ PMSF and $0.33 \mathrm{mg} \mathrm{ml}^{-1}$ benzamidine).

\section{Protein purification}

Protein purifications were performed at $4{ }^{\circ} \mathrm{C}$. After collection and resuspension, cells of the SARS-CoV- 2 nsp12 expression were immediately sonicated for cell lysis. Lysates were subsequently cleared by centrifugation $\left(87,207 \mathrm{~g}, 4^{\circ} \mathrm{C}, 30 \mathrm{~min}\right)$ and ultracentrifugation $\left(235,000 \mathrm{~g}, 4^{\circ} \mathrm{C}, 60 \mathrm{~min}\right)$. The supernatant containing $\mathrm{nsp} 12$ was filtered using a $5-\mu \mathrm{m}$ syringe filter, followed by filtration with a $0.8-\mu \mathrm{m}$ syringe filter (Millipore) and applied onto a His Trap HP $5 \mathrm{ml}$ (GE Healthcare), preequilibrated in lysis buffer $(300 \mathrm{mM} \mathrm{NaCl}, 50 \mathrm{mM} \mathrm{Na}$-HEPES $\mathrm{pH} 7.4,10 \%$ (v/v) glycerol, $30 \mathrm{mM}$ imidazole pH 8.0,3 $\mathrm{mM} \mathrm{MgCl}_{2}, 5 \mathrm{mM}$

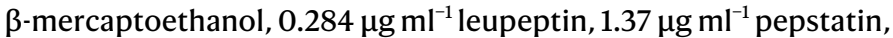
$0.17 \mathrm{mg} \mathrm{ml}^{-1}$ PMSF and $0.33 \mathrm{mg} \mathrm{ml}^{-1}$ benzamidine). After application of the sample, the column was washed with 6 column volumes $(\mathrm{CV})$ high-salt buffer (1,000 mM NaCl, 50 mM Na-HEPES pH 7.4, 10\% (v/v) glycerol,
$30 \mathrm{mM}$ imidazole $\mathrm{pH} 8.0,3 \mathrm{mM} \mathrm{MgCl}, 5 \mathrm{mM} \beta$-mercaptoethanol, $0.284 \mu \mathrm{g} \mathrm{ml}^{-1}$ leupeptin, $1.37 \mathrm{\mu g} \mathrm{ml}^{-1}$ pepstatin, $0.17 \mathrm{mg} \mathrm{ml}^{-1} \mathrm{PMSF}$ and $0.33 \mathrm{mg} \mathrm{ml}^{-1}$ benzamidine), and $6 \mathrm{CV}$ lysis buffer. The HisTrap was then attached to an XKcolumn16/20 (GEHealthcare), prepacked with amylose resin (New England Biolabs), which was pre-equilibrated in lysis buffer. The protein was eluted from the HisTrap column directly onto the amylose column using nickel elution buffer $(300 \mathrm{mM} \mathrm{NaCl}, 50 \mathrm{mM} \mathrm{Na}$-HEPES $\mathrm{pH} 7.4,10 \%$ (v/v) glycerol, $500 \mathrm{mM}$ imidazole pH 8.0, $3 \mathrm{mM} \mathrm{MgCl}_{2}$ and $5 \mathrm{mM} \beta$-mercaptoethanol). The HisTrap column was then removed and the amylose column was washed with $10 \mathrm{CV}$ of lysis buffer. Protein was eluted from the amylose column using amylose elution buffer (300 mM NaCl, $50 \mathrm{mM} \mathrm{Na-HEPES} \mathrm{pH} \mathrm{7.4,10 \%} \mathrm{(v/v)} \mathrm{glycerol,} 116.9 \mathrm{mM}$ maltose, $30 \mathrm{mM}$ imidazole $\mathrm{pH} 8.0$ and $5 \mathrm{mM} \beta$-mercaptoethanol). Peak fractions were assessed via SDS-PAGE and staining with Coomassie. Peak fractions containing nsp12 were pooled and mixed with $8 \mathrm{mg}$ of His-tagged TEV protease (about $80 \%(\mathrm{w} / \mathrm{w})$ ). After $12 \mathrm{~h}$ of protease digestion at $4{ }^{\circ} \mathrm{C}$, protein was applied to a HisTrap column equilibrated in lysis buffer to remove uncleaved nsp12, $6 \times \mathrm{His}-\mathrm{MBP}$ and TEV. Subsequently, the flow-through containing nsp12 was applied to a HiTrap Heparin $5 \mathrm{ml}$ column (GE Healthcare). The flow-through containing nsp12 was collected and concentrated in a MWCO 50,000 Amicon Ultra Centrifugal Filter unit (Merck). The concentrated sample was applied to a HiLoad S200 16/600 pg equilibrated in size-exclusion buffer (300 mM NaCl, $20 \mathrm{mM} \mathrm{Na-HEPES} \mathrm{pH} \mathrm{7.4,10 \%} \mathrm{(v/v)} \mathrm{glycerol,} 1 \mathrm{mM} \mathrm{MgCl}_{2}$, $1 \mathrm{mM}$ TCEP). Peak fractions were assessed by SDS-PAGE and Coomassie staining. Peak fractions were pooled and concentrated in a MWCO 50,000 Amicon Ultra Centrifugal Filter (Merck). The concentrated protein with a final concentration of $102 \mu \mathrm{M}$ was aliquoted, flash-frozen and stored at $-80^{\circ} \mathrm{C}$ until use.

SARS-CoV-2 nsp8 and nsp7 were purified separately using the same purification procedure, as follows. After cell collection and resuspension in lysis buffer, the protein of interest was immediately sonicated. Lysates were subsequently cleared by centrifugation $\left(87.200 \mathrm{~g}, 4^{\circ} \mathrm{C}\right.$, $30 \mathrm{~min}$ ). The supernatant was applied to a HisTrap HP $5 \mathrm{ml}$ column (GE Healthcare), preequilibrated in lysis buffer. The column was washed with 9.5 CV high-salt buffer (1,000 mM NaCl, $50 \mathrm{mM} \mathrm{Na-HEPES} \mathrm{pH} \mathrm{7.4,}$ $10 \%$ (v/v) glycerol, $30 \mathrm{mM}$ imidazole $\mathrm{pH} 8.0,5 \mathrm{mM} \beta$-mercaptoethanol, $0.284 \mu \mathrm{g} \mathrm{ml}^{-1}$ leupeptin, $1.37 \mathrm{\mu g} \mathrm{ml}^{-1}$ pepstatin, $0.17 \mathrm{mg} \mathrm{ml}^{-1} \mathrm{PMSF}$ and $0.33 \mathrm{mg} \mathrm{ml}^{-1}$ benzamidine), and $9.5 \mathrm{CV}$ low-salt buffer $(150 \mathrm{mM} \mathrm{NaCl}$, $50 \mathrm{mM}$ Na-HEPES pH 7.4,10\% (v/v) glycerol, $30 \mathrm{mM}$ imidazole $\mathrm{pH} 8.0$ and $5 \mathrm{mM} \beta$-mercaptoethanol). The sample was then eluted using nickel elution buffer (150 mM NaCl, $50 \mathrm{mM} \mathrm{Na}$-HEPES pH 7.4,10\% (v/v) glycerol, $500 \mathrm{mM}$ imidazole $\mathrm{pH} 8.0$ and $5 \mathrm{mM} \beta$-mercaptoethanol). The eluted protein was dialysed in dialysis buffer $(150 \mathrm{mM} \mathrm{NaCl}, 50 \mathrm{mM} \mathrm{Na}$-HEPES $\mathrm{pH} 7.4,10 \%(\mathrm{v} / \mathrm{v})$ glycerol and $5 \mathrm{mM} \beta$-mercaptoethanol) in the presence of $2 \mathrm{mg}$ His-tagged TEV protease (nsp7: about 10\% (w/w), nsp8: about $6 \%(\mathrm{w} / \mathrm{w}))$ at $4{ }^{\circ} \mathrm{C}$. After $12 \mathrm{~h}$, imidazole $\mathrm{pH} 8.0$ was added to a final concentration of $30 \mathrm{mM}$. The dialysed sample was subsequently applied to a HisTrap HP $5 \mathrm{ml}$ column (GE Healthcare), preequilibrated in dialysis buffer. The flow-through that contained the protein of interest was then applied to a HiTrap Q $5 \mathrm{ml}$ column (GE Healthcare). The Q column flow-through containing nsp8 or nsp7 was concentrated using a MWCO 3,000 Amicon Ultra Centrifugal Filter (Merck) and applied to a HiLoad S200 16/600 pg equilibrated in size exclusion buffer $(150 \mathrm{mM} \mathrm{NaCl}$, $20 \mathrm{mM}$ Na-HEPES pH 7.4, 5\% (v/v) glycerol, $1 \mathrm{mM} \mathrm{TCEP).} \mathrm{Peak} \mathrm{fractions}$ were assessed by SDS-PAGE and Coomassie staining. Peak fractions were pooled. Nsp7 with a final concentration of $418 \mu \mathrm{M}$ was aliquoted, flash-frozen and stored at $-80^{\circ} \mathrm{C}$ until use. Nsp 8 with a final concentration of $250 \mu \mathrm{M}$ was aliquoted, flash-frozen and stored at $-80^{\circ} \mathrm{C}$ until use. All protein identities were confirmed by mass spectrometry.

\section{RNA extension assays}

All RNA oligonucleotides were purchased from Integrated DNA Technologies. The RNA sequence used for the transcription assay is /56-FAM/rUrUrU rUrCrA rUrGrC rUrArC rGrCrG rUrArG rUrUr UrUrC 
rUrArC rGrCrG. We designed a minimal substrate by connecting the template RNA to the RNA primer by a tetraloop, to protect the blunt ends of the RNA duplex and to ensure efficient annealing. RNA was annealed in $50 \mathrm{mM} \mathrm{NaCl}$ and $10 \mathrm{mM} \mathrm{Na}$-HEPES pH 7.5 by heating the solution to $75^{\circ} \mathrm{C}$ and gradually cooling to $4{ }^{\circ} \mathrm{C}$. RNA extension reactions contained RNA $(5 \mu \mathrm{M})$, nsp12 $(5 \mu \mathrm{M})$, nsp8 $(15 \mu \mathrm{M})$ and nsp7 $(15 \mu \mathrm{M})$ in $100 \mathrm{mMNaCl}, 20 \mathrm{mMNa}-\mathrm{HEPESpH} 7.5,5 \%(\mathrm{v} / \mathrm{v})$ glycerol, $10 \mathrm{mMMgCl}_{2}$ and $5 \mathrm{mM} \beta$-mercaptoethanol. Reactions were incubated at $37^{\circ} \mathrm{C}$ for $5 \mathrm{~min}$ and the RNA extension was initiated by addition of NTPs $(150 \mu \mathrm{MUTP}$, GTP and CTP, and $300 \mu \mathrm{M}$ ATP). Reactions were stopped by the addition of $2 \times$ stop buffer (7 M urea, 50 mM EDTA pH 8.0,1× TBE buffer). Samples were digested with proteinase $\mathrm{K}$ (New England Biolabs) and RNA products were separated on $8 \mathrm{~cm} \times 8 \mathrm{~cm} 20 \%$ acrylamide gels in $1 \times$ TBE buffer supplemented with $8 \mathrm{M}$ urea. 6-FAM-labelled RNA products were visualized by Typhoon 95000 FLA Imager (GE Healthcare Life Sciences).

\section{Cryo-EM sample preparation and data collection}

An RNA scaffold for RdRP-RNA complex formation was annealed by mixing equimolar amounts of two RNA strands (5'-rUrUrU rUrCrA rUrGrC rUrArC rGrCrG rUrArG-3'; 56-FAM/rCrUrA rCrGrC rG-3') (IDT Technologies) in annealing buffer (10 mM Na-HEPES pH 7.4, $50 \mathrm{mM}$ $\mathrm{NaCl}$ ) and heating to $75^{\circ} \mathrm{C}$, followed by step-wise cooling to $4{ }^{\circ} \mathrm{C}$. For complex formation, $1.2 \mathrm{nmol}$ of purified nsp12 was mixed with a 1.2-fold molar excess of RNA scaffold and sixfold molar excess of each nsp8 and nsp7. After incubation at room temperature for $10 \mathrm{~min}$, the EC was subjected to size exclusion chromatography on a Superdex 200 Increase 3.2/300 equilibrated with complex buffer (20 mM Na-HEPES $\left.\mathrm{pH} 7.4,100 \mathrm{mM} \mathrm{NaCl}, 1 \mathrm{mM} \mathrm{MgCl}{ }_{2}, 1 \mathrm{mM} \mathrm{TCEP}\right)$. Peak fractions with a volume of $100 \mu \mathrm{l}$ (absorbance at $280 \mathrm{~nm}$ of $0.155 \mathrm{AU}, 2-\mathrm{mm}$ path length) corresponding to a nucleic-acid-rich high-molecular weight population (as judged by absorbance at $260 \mathrm{~nm}$ ) were pooled and concentrated in a MWCO 30,000 Vivaspin 500 concentrator (Sartorius) to approximately $20 \mu \mathrm{l}$. Three $\mu \mathrm{l}$ of RdRp-RNA complex were mixed with $0.5 \mu \mathrm{l}$ of octyl $\beta$-D-glucopyranoside (0.003\% final concentration) and applied to freshly glow-discharged R $2 / 1$ holey carbon grids (Quantifoil). Prior to flash freezing in liquid ethane, the grid was blotted for $6 \mathrm{~s}$ with a blot force of 5 using a Vitrobot Mark IV (Thermo Fisher Scientific) at $4{ }^{\circ} \mathrm{C}$ and $100 \%$ humidity.

Cryo-EM data collection was performed with SerialEM ${ }^{28}$ using a Titan Krios transmission electron microscope (Thermo Fisher Scientific) operated at $300 \mathrm{keV}$. Images were acquired in EFTEM mode with a slit width of $20 \mathrm{eV}$ using a GIF quantum energy filter and a K3 direct electron detector (Gatan) at a nominal magnification of $105,000 \times$ corresponding to a calibrated pixel size of $0.834 \AA$ per pixel. Exposures were recorded in counting mode for $2.2 \mathrm{~s}$ with a dose rate of $19 e^{-}$per pixel per s resulting in a total dose of $60 e^{-}$per $\AA^{2}$ that was fractionated into 80 movie frames. Because initial processing showed that the particles adopted only a limited number of orientations in the vitreous ice layer, a total of 8,168 movies were collected at $30^{\circ}$ stage tilt to yield a broader distribution of orientations. Untilted data were discarded. Motion correction, dose weighting, CTF estimation, particle picking and extraction were performed using Warp ${ }^{29}$.

\section{Cryo-EM data processing and analysis}

We exported the 1.3 million particles from Warp ${ }^{29}$ to cryoSPARC $^{30}$, and the particles were subjected to 2D classification. Twenty-five per cent of the particles were selected from classes deemed to represent the polymerase, and refined against a synthetic reference prepared from the model with the Protein Data Bank (PDB) code 6M71. Ab initio refinement was performed using particles from bad $2 \mathrm{D}$ classes to obtain five 3D classes of 'junk'. These five classes and the first polymerase reconstruction were used as starting references to sort the initial 1.3 million particles in supervised 3D classification rather than $2 \mathrm{D}$, as the latter tended to exclude less abundant projection directions. Five hundred and fourteen thousand particles (39\%) from the resulting polymerase class were subjected to another ab initio refinement to obtain five starting references containing four junk classes and the complex of interest. These classes were used as starting references in another supervised 3D classification. Four hundred and eighteen thousand particles (82\%) from the class representing the complex were exported from cryoSPARC to RELION $3.0^{31}$. There, all particles were refined in $3 \mathrm{D}$ against the reconstruction previously obtained in cryoSPARC, using a mask including only the core part of the polymerase and a short segment of upstream RNA to obtain a 3.1 Å reconstruction. CTF refinement and another round of 3D refinement improved the resolution further to $2.9 \AA$ (map 1 in Extended Data Fig. 2a-c). Particles were re-extracted at $1.3 \AA$ per pixel in a bigger box in Warp to accommodate distant parts of the RNA. Unsupervised 3D classification with local alignment was performed to obtain two classes (with nsp8b present and without). One hundred and seventy-two thousand particles with nsp8b present were finally subjected to global (map 2 in Extended Data Fig. $2 a-c)$ and focused 3D refinement using a mask including the RNA, nsp8a and nsp8b (map 3 in Extended Data Fig. 2a-c).

\section{Model building and refinement}

To build the atomic model of the RdRp-RNA complex, we started from the structure of the freeSARS-CoV-2 RdRp (PDB 6M71) that was recently adjusted by T. Croll (available through the Coronavirus Structural Task Force by A. Thorn at https://github.com/thorn-lab/coronavirus_ structural_task_force/tree/master/pdb/rna_polymerase-nsp7-nsp8/ SARS-CoV-2/6m71/isolde). The structure was rigid-body fit into the cryo-EM reconstruction and adjusted manually in $\mathrm{Coot}^{32}$. Unmodelled density remained for helical segments in the $\mathrm{N}$-terminal regions of both copies of nsp8. These nsp 8 extensions were modelled by superimposing the nsp8 model (PDB 2AHM; chain $\mathrm{H}$ ) from the crystal structure of the nsp7-nsp8 hexadecamer ${ }^{17}$, in which the far $\mathrm{N}$-terminal region of nsp8 adopts the same fold. Nsp8a (chain B) showed weaker density than nsp8b (chain $D$ ), but the register was faithfully determined by superimposing well-resolved parts (residues 80-97). The most $\mathrm{N}$-terminal helices in nsp8a and nsp8b (residues 6-31) were only visible after low-pass filtering of maps to the local resolution of $6 \AA$ and were modelled by superposition of the crystal structure of nsp8 (PDB 2AHM; chain $\mathrm{H}$ ) with residues $33-55$, which positioned these helices within the density in the low-pass-filtered map. Side chains for residues 6-31 were subbed. Careful inspection of the remaining A-form RNA density revealed that in our complex, instead of the originally designed short template-primer duplex (see 'Cryo-EM sample preparation and data collection'), four copies of one of the RNA oligonucleotides were annealed to form a pseudo-continuous long RNA duplex. Annealing was mediated by a 10-bp self-complementary region within this RNA oligonucleotide (Extended Data Fig. 1c). Nucleotides 5-18 of four RNA strands were modelled, whereas the flapped-out nucleotides 1-4 were invisible and excluded. The model was real-space-refined using phenix.refine ${ }^{33}$ against a composite map of the focused refinement (maps 1 and 3 ) and global reconstructions (map 2) generated in phenix.combine_focused_maps and shows excellent stereochemistry (Extended Data Table 1). Figures were prepared with PyMol and Chimera $^{34}$.

\section{Reporting summary}

Further information on research design is available in the Nature Research Reporting Summary linked to this paper.

\section{Data availability}

The electron potential reconstructions and structure coordinates have been deposited with the Electron Microscopy Database under accession code EMD-11007, and with the PDB under accession code 6YYT. We additionally deposited the raw cryo-EM data in the EMPIAR database, under accession code EMPIAR-10409. 
27. Vos, S. M. et al. Architecture and RNA binding of the human negative elongation factor. elife 5, e14981 (2016)

28. Mastronarde, D. N. Automated electron microscope tomography using robust prediction of specimen movements. J. Struct. Biol. 152, 36-51 (2005)

29. Tegunov, D. \& Cramer, P. Real-time cryo-electron microscopy data preprocessing with Warp. Nat. Methods 16, 1146-1152 (2019)

30. Punjani, A., Rubinstein, J. L., Fleet, D. J. \& Brubaker, M. A. cryoSPARC: algorithms for rapid unsupervised cryo-EM structure determination. Nat. Methods 14, 290-296 (2017).

31. Zivanov, J., Nakane, T. \& Scheres, S. H. W. A Bayesian approach to beam-induced motion correction in cryo-EM single-particle analysis. IUCrJ 6, 5-17 (2019).

32. Emsley, P., Lohkamp, B., Scott, W. G. \& Cowtan, K. Features and development of Coot. Acta Crystallogr. D 66, 486-501 (2010).

33. Afonine, P. V. et al. Real-space refinement in PHENIX for cryo-EM and crystallography. Acta Crystallogr. D 74, 531-544 (2018).

34. Huang, C. C., Meng, E. C., Morris, J. H., Pettersen, E. F. \& Ferrin, T. E. Enhancing UCSF Chimera through web services. Nucleic Acids Res. 42, W478-W484 (2014).

Acknowledgements We thank all members of the Department of Molecular Biology at the Max-Planck-Institute for Biophysical Chemistry for support; J. Schmitzova for helpful discussions and advice; and H. Urlaub for mass spectrometry. H.S.H. was supported by the Deutsche Forschungsgemeinschaft (FOR2848). P.C. was supported by the Deutsche Forschungsgemeinschaft (SFB860, SPP2191), Germany's Excellence Strategy (EXC 2067/ 1-390729940), the ERC Advanced Investigator Grant TRANSREGULON (grant agreement no. 693023) and the Volkswagen Foundation.

Author contributions H.S.H., G.K., L.F., C.D. and D.T. designed and carried out experiments and data analysis. P.C. designed and supervised research. All authors interpreted data and wrote the manuscript.

Competing interests The authors declare no competing interests.

Additional information

Supplementary information is available for this paper at https://doi.org/10.1038/s41586-0202368-8.

Correspondence and requests for materials should be addressed to P.C.

Peer review information Nature thanks Bruno Canard and the other, anonymous, reviewer(s) for their contribution to the peer review of this work. Peer reviewer reports are available. Reprints and permissions information is available at http://www.nature.com/reprints. 

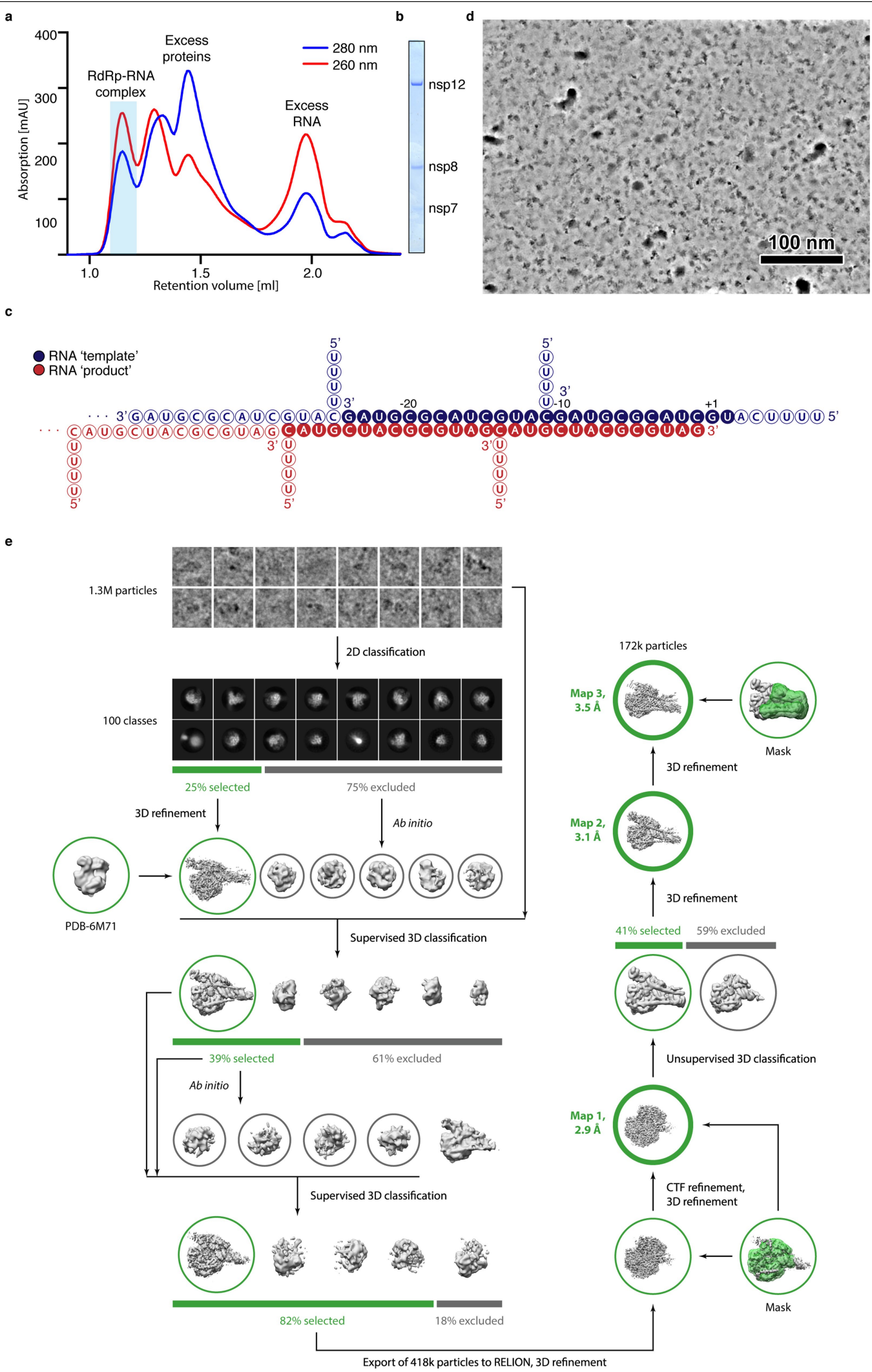

Extended Data Fig. 1 | Cryo-EM analysis. This figure is related to Figs. 1, 2. a, Purification of the RdRp-RNA complex by size exclusion chromatography. The peak used for structural analysis is highlighted in blue. The experiment was performed once. b. Exemplary SDS-PAGE analysis of purified complex, with RdRp subunits labelled. The experiment was performed once. $c$, RNA duplex scaffold formed by oligomerization of a short pseudo-palindromic RNA. The base pairing depicted gave rise to a pseudo-continuous A-form duplex. Solid and hollow circles show RNA nucleotides that were included in the structure or not visible, respectively. d, Example de-noised micrograph calculated from two independently measured half sets of 40 frames each. Scale bar, $100 \mathrm{~nm}$.e, Cryo-EM processing tree. 
a
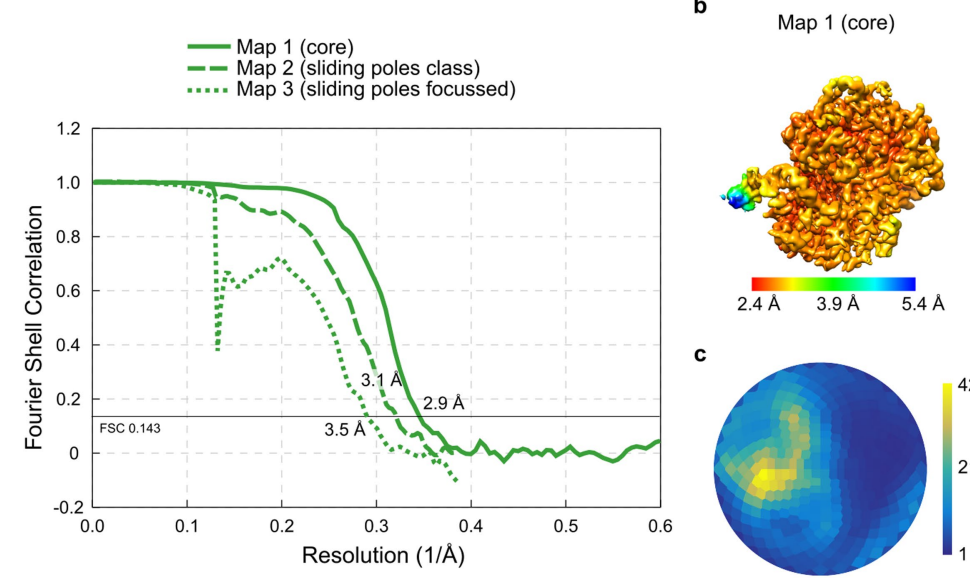

c

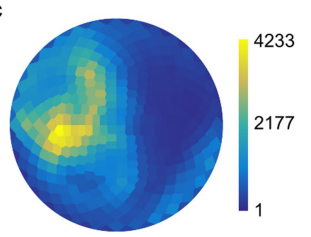

Map 2 (sliding poles class)
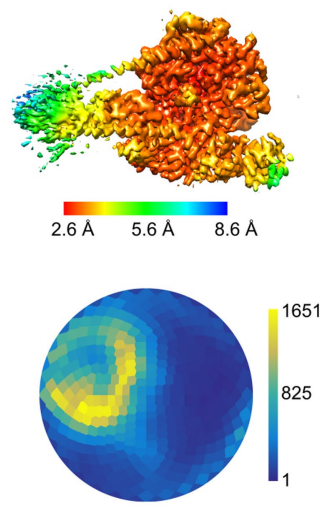

Map 3 (sliding poles focussed)
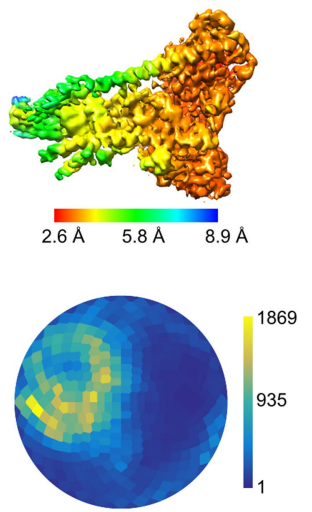

d
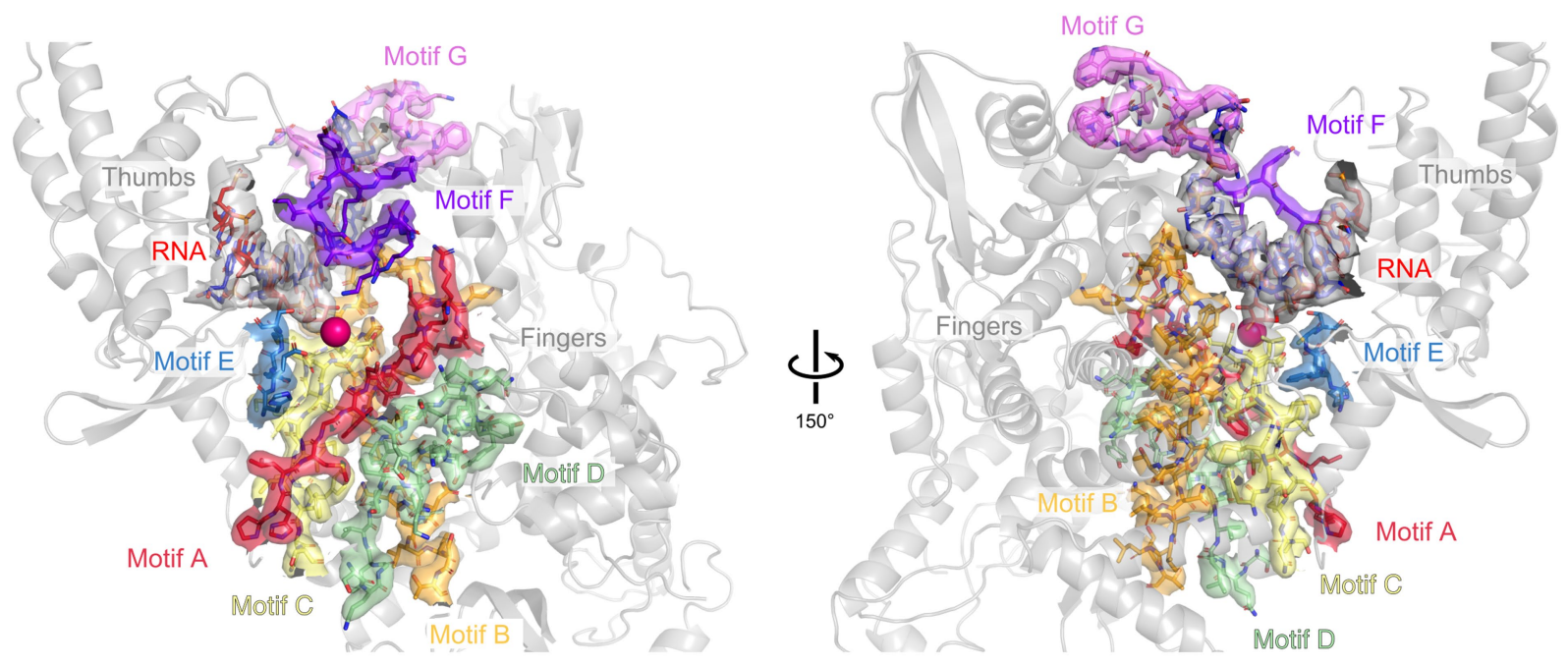

e

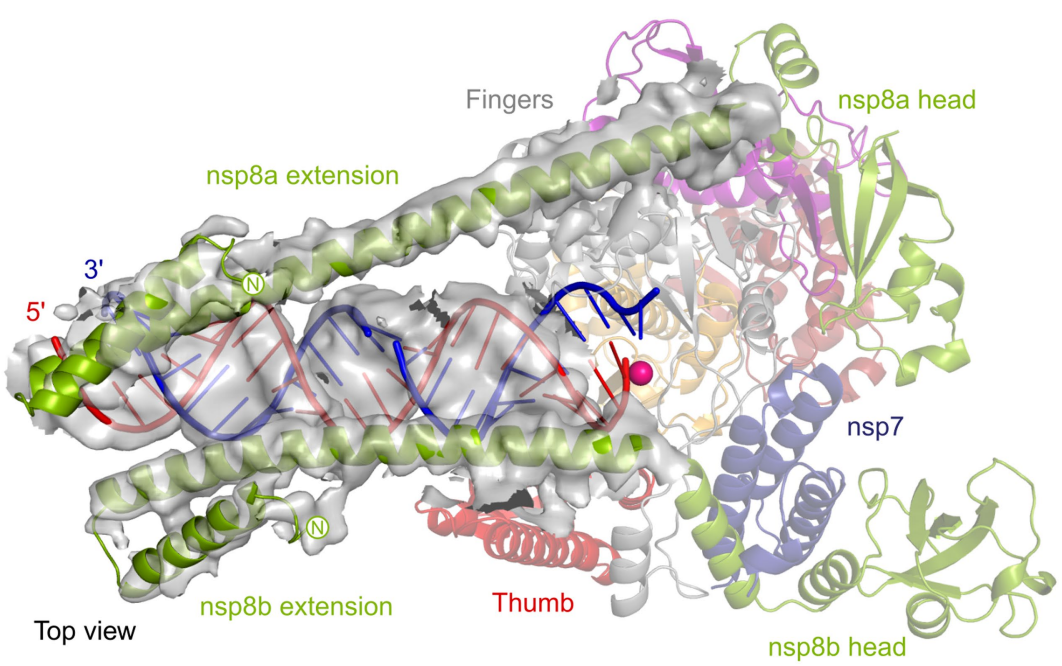

f

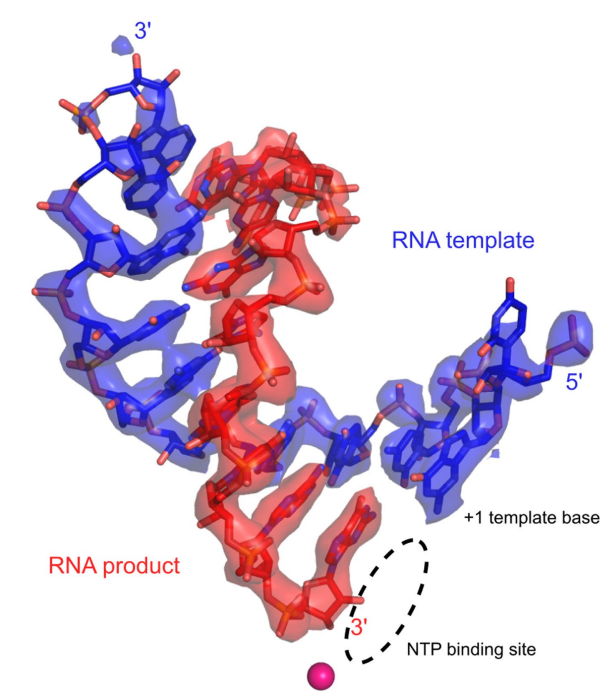

Extended Data Fig. 2 |Cryo-EM reconstructions. This figure is related to Fig. 2. a, Fourier shell correlation (FSC) plots for reported reconstructions and resolution estimates. $\mathbf{b}$, Local resolution distribution for the reported reconstructions. c, Angular distribution plots. Scale shows the number of particles assigned to a particular angular bin. Blue, a low number of particles; yellow, a high number of particles. d, Cryo-EM map for the RdRp active centre region, including elements with sequence motifs $A-G$. The active site is indicated by a magenta sphere.e, Cryo-EM map for the RNA duplex and the nsp8 extensions. The active site is indicated by a magenta sphere.f, Cryo-EM map for the RNA duplex in the active site. The active site is indicated with a magenta sphere, and the NTP site with a dashed circle. 
a

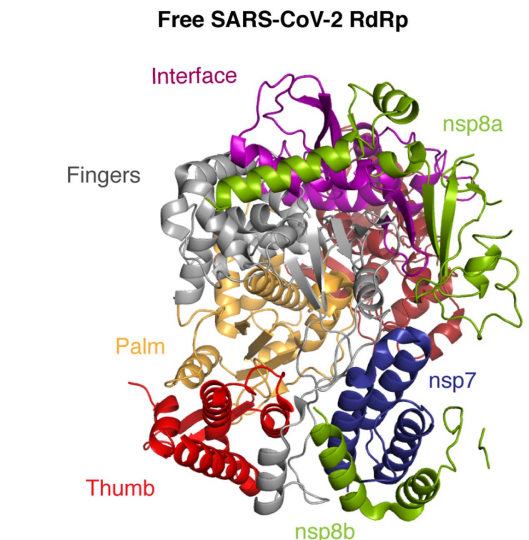

Top view

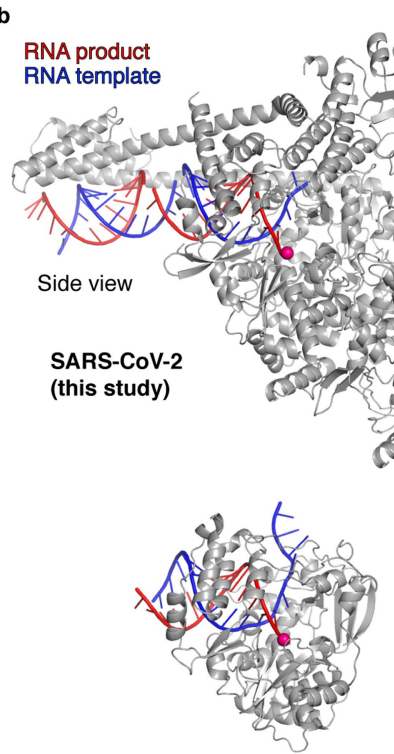

Poliovirus

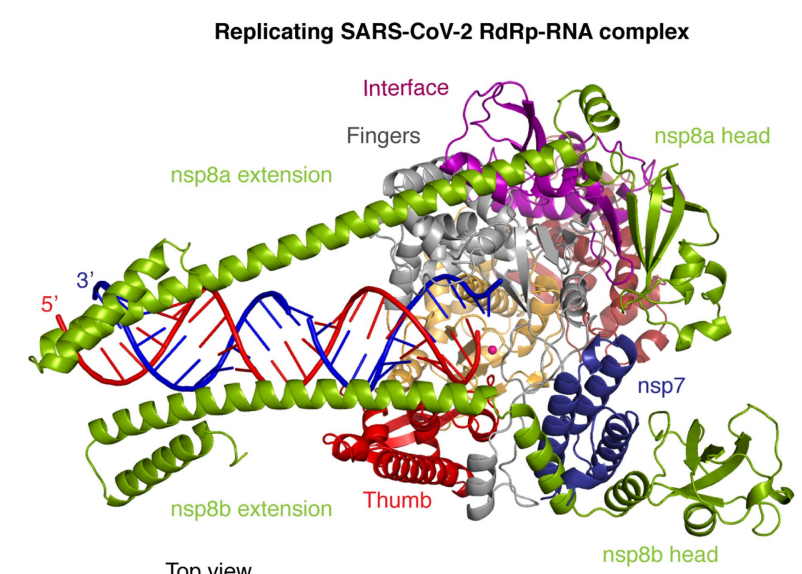

Top view

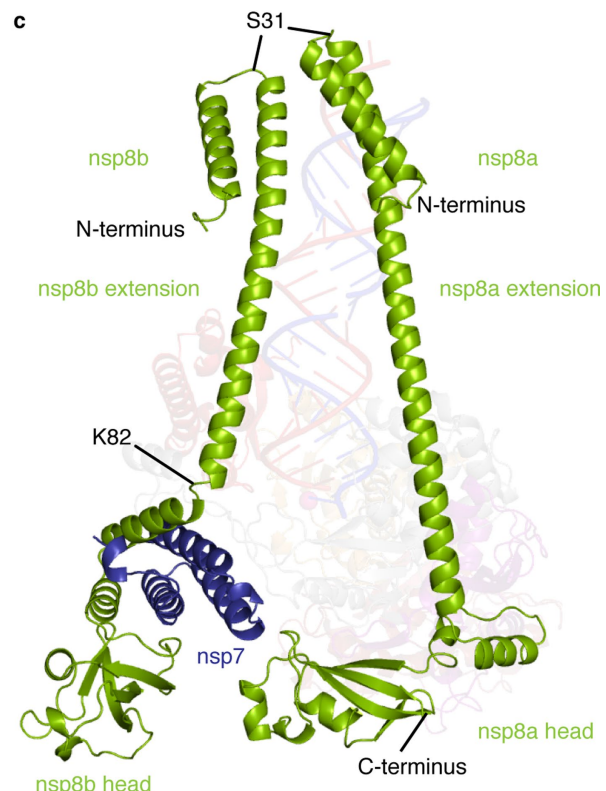

d

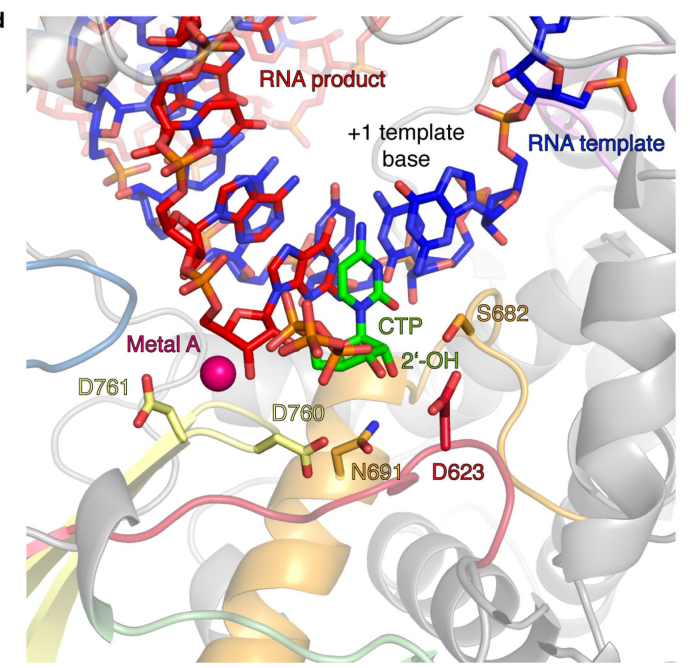

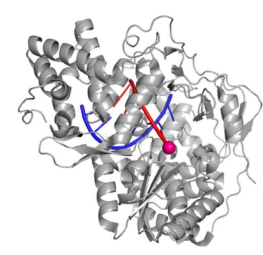

Hepatitis $\mathrm{C}$ virus

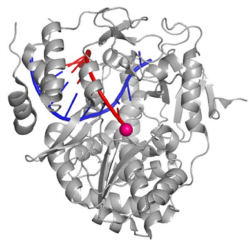

Norovirus
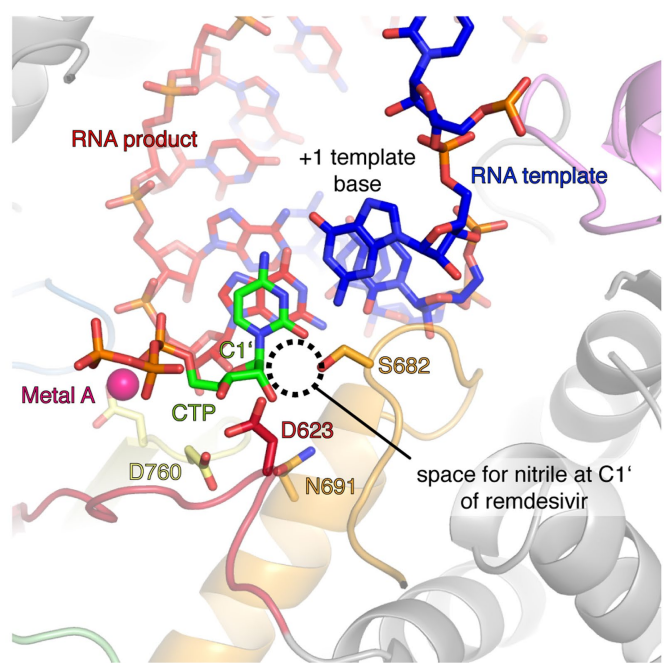

Extended Data Fig. 3 | See next page for caption. 
Extended Data Fig. 3 | Structural comparisons. This figure is related to Figs. 2, 3.a, Comparison of the free SARS-CoV-2 RdRp structure ${ }^{15}$ (left) with the replicating RdRp-RNA complex (right). Colour code as in Fig. 2.b, Similar location and orientation of the RNA-template product duplex in RdRp complexes of SARS-CoV-2 virus (top left), hepatitis $\mathrm{C}_{\text {virus }}{ }^{19}$ (top right), poliovirus ${ }^{20}$ (bottom left) and norovirus ${ }^{21}$ (bottom right). Structures are shown as ribbon models, with RNA template and product strands in blue and red, respectively. An active-site metal ion is shown as a magenta sphere. Side view as defined in Fig. 2.c, The two nsp8 copies adopt different folds within the RdRpRNA complex. Top view as in a but rotated by $90^{\circ}$. Nsp 8 and $n s p 7$ are opaque and nsp12 is transparent. The nsp 8 b extension has a kink around residue 82 , which may be stabilized by elements of nsp7 and nsp12.d, Model of substrate NTP in the RdRp active site. ACTP substrate was placed after superposition of the structure of the norovirus RdRp-nucleic acid comple ${ }^{21}$. Colouring as in Fig. 3b. Active-site residues D760, D761, N691, S682 and D623 are shown as sticks, and the modelled active-site metal ion is shown as a magenta sphere. When the nucleoside triphosphate form of remdesivir would bind in the NTP site, the nitrile group connected to the ribose $\mathrm{Cl}^{\prime}$ position would be accommodated in the space indicated by the dashed circle. 
Extended Data Table 1 | Cryo-EM data collection, refinement and validation statistics

\section{Cryo-EM data collection, refinement and validation statistics}

SARS-CoV-2 RdRp-RNA complex (PDB 6YYT)

$\begin{array}{cccc}\text { Map 1 core } & \text { Map 2 sliding poles class } & \text { Map 3 sliding } & \text { Composite map } \\ \text { (EMD-11007) } & \text { (EMD-11007) } & \begin{array}{c}\text { poles focused } \\ \text { (EMD-11007) }\end{array} & \text { (EMD-11007) }\end{array}$

\section{Data collection and processing}

Magnification

Voltage (kV)

Electron exposure $\left(\mathrm{e}-/ \AA^{2}\right)$

$$
\begin{gathered}
105,000 \mathrm{x} \\
300 \\
60 \\
0.5-1.5 \\
0.834 \\
\mathrm{C} 1 \\
1,300,000 \\
0.834 \\
418,000 \\
2.9 \\
0.143 \\
2.4-5.4 \\
-93
\end{gathered}
$$
$105,000 \mathrm{x}$
300
60

$105,000 \mathrm{x}$

300

Pixel size $(\AA)$

$0.5-1.5$

0.834

Initial particle images (no.)

Processing pixel size $(\AA)$

Final particle images (no.)

Map resolution $(\AA)$

FSC threshold

Map resolution range $(\AA)$

Map sharpening $B$ factor $\left(\AA^{2}\right)$

C1

60
$0.5-1.5$
0.834

$1,300,000$

1.3

171,400

3.2

0.143

$2.6-8.6$

$-60$

$\mathrm{C} 1$

$1,300,000$

1.3

171,400

3.5

0.143

$2.6-8.9$

$-95$

\section{Refinement}

Initial model used (PDB code)

Model resolution ( $\AA$ )

FSC threshold

Model resolution range $(\AA)$

Model composition

Non-hydrogen atoms

Protein residues

Ligands

$B$ factors $\left(\AA^{2}\right)$

Protein

Ligand

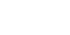

R.m.s. deviations

Bond lengths $(\AA)$

Bond angles $\left({ }^{\circ}\right)$

Validation

MolProbity score

Clashscore

Poor rotamers (\%)

Ramachandran plot

Favored (\%)

Allowed (\%)

0.00 


\section{Reporting Summary}

Nature Research wishes to improve the reproducibility of the work that we publish. This form provides structure for consistency and transparency in reporting. For further information on Nature Research policies, see Authors \& Referees and the Editorial Policy Checklist.

\section{Statistics}

For all statistical analyses, confirm that the following items are present in the figure legend, table legend, main text, or Methods section.

n/a Confirmed

\ $\square$ The exact sample size $(n)$ for each experimental group/condition, given as a discrete number and unit of measurement

Х $\square$ A statement on whether measurements were taken from distinct samples or whether the same sample was measured repeatedly

$\square$ The statistical test(s) used AND whether they are one- or two-sided

$\triangle$ Only common tests should be described solely by name; describe more complex techniques in the Methods section.

Х $\square$ A description of all covariates tested

Х $\square$ A description of any assumptions or corrections, such as tests of normality and adjustment for multiple comparisons

A A full description of the statistical parameters including central tendency (e.g. means) or other basic estimates (e.g. regression coefficient)

$\triangle \square$ AND variation (e.g. standard deviation) or associated estimates of uncertainty (e.g. confidence intervals)

$\square$ For null hypothesis testing, the test statistic (e.g. $F, t, r$ ) with confidence intervals, effect sizes, degrees of freedom and $P$ value noted

$\triangle \square$ Give $P$ values as exact values whenever suitable.

Х $\square$ For Bayesian analysis, information on the choice of priors and Markov chain Monte Carlo settings

Х $\square$ For hierarchical and complex designs, identification of the appropriate level for tests and full reporting of outcomes

Х $\square$ Estimates of effect sizes (e.g. Cohen's $d$, Pearson's $r$ ), indicating how they were calculated

Our web collection on statistics for biologists contains articles on many of the points above.

\section{Software and code}

Policy information about availability of computer code

Data collection Serial EM 3.8 beta 8

Data analysis RELION 3.0 beta-2, UCSF Chimera 1.13, UCSF ChimeraX v0.8, Pymol 2.2.2, Coot 0.9, Warp v1.0.7, PHENIX 1.18, cryoSPARC 2.14.2

For manuscripts utilizing custom algorithms or software that are central to the research but not yet described in published literature, software must be made available to editors/reviewers. We strongly encourage code deposition in a community repository (e.g. GitHub). See the Nature Research guidelines for submitting code \& software for further information.

\section{Data}

Policy information about availability of data

All manuscripts must include a data availability statement. This statement should provide the following information, where applicable:

- Accession codes, unique identifiers, or web links for publicly available datasets

- A list of figures that have associated raw data

- A description of any restrictions on data availability

The electron density reconstructions and structure coordinates were deposited with the Electron Microscopy Database (EMDB) under accession code EMD-11007 and with the Protein Data Bank (PDB) under accession code 6YYT.

\section{Field-specific reporting}

Please select the one below that is the best fit for your research. If you are not sure, read the appropriate sections before making your selection. \ Life sciences 


\section{Life sciences study design}

All studies must disclose on these points even when the disclosure is negative.

Sample size No statistical methods were used to predetermine sample size.

Data exclusions No data were excluded from the analyses.

Replication All attempts at replication were successful. Cryo-EM single particle analysis inherently relies on averaging over a large number of independent observations.

Randomization Samples were not allocated to groups.

Blinding Investigators were not blinded during data acquisition and analysis because it is not a common procedure for the methods employed.

\section{Reporting for specific materials, systems and methods}

We require information from authors about some types of materials, experimental systems and methods used in many studies. Here, indicate whether each material, system or method listed is relevant to your study. If you are not sure if a list item applies to your research, read the appropriate section before selecting a response.

Materials \& experimental systems

\begin{tabular}{l|l}
\hline Involved in the study \\
$\square$ Antibodies \\
$\square$ Eukaryotic cell lines \\
$\square$ Palaeontology \\
$\square$ Animals and other organisms \\
$\square$ Clinical data
\end{tabular}

\section{Eukaryotic cell lines}

Policy information about cell lines

Cell line source(s)

Hi5 cells: Expression Systems, Tni Insect cells in ESF921 media, item 94-002F

Sf9 cells: ThermoFisher, Catalogue Number 12659017, Sf9 cells in Sf-9000TM III SFM

Sf21 cells: Expression Systems, SF21 insect cells in ESF921 medium, Item 94-003F

Authentication

Mycoplasma contamination

Commonly misidentified lines (See ICLAC register)
None of the cell lines were authenticated.

\begin{tabular}{|c|c|}
\hline $\mathrm{n} / \mathrm{a}$ & Involved in the study \\
\hline$\bigotimes$ & $\square$ ChIP-seq \\
\hline$\bigotimes$ & $\square$ Flow cytometry \\
\hline Х & MRI-based neuroimaging \\
\hline
\end{tabular}

Cell lines were not tested for mycoplasma contamination.

No commonly misidentified cell lines were used. 